\title{
CORRIGENDUM
}

\section{Factors which enhance or inhibit social support: a mixed-methods analysis of social networks in older women - CORRIGENDUM}

\section{DEIRDRE MCLAUGHLIN, JON ADAMS, DIMITRIOS VAGENAS and ANNETTE DOBSON}

doi:10.1017/So144686X10ooo668, Published by Cambridge University Press 02 November 2010.

On p21 of Volume 31 under 'The outcome variables'. The range of scores reported in the final sentence in this paragraph is incorrect and should read as follows:

Network scores ranged from 4 to 12 with higher scores indicating more social contacts; the distribution of the scores was approximately normal.

\section{References}

McLaughlin, D., Adams, J., Vagenas, D. and Dobson, A. 2010. Factors which enhance or inhibit social support: a mixed-methods analysis of social networks in older women. Ageing $\mathcal{G}$ Society 31, 1, 201 1, 18-33. 